\title{
Trading on the information content of open interest: Evidence from the US equity options market
}

\author{
Rafiqul Bhuyan* and Mo Chaudhury \\ * Department of Management, College of Business Administration, California State \\ University, 6000 J Street, Sacramento, CA 95819-6088, USA. Tel: +1 916278 6459; \\ E-mail: Bhuyanr@csus.edu
}

Received (in revised form): 5th January, 2005

\begin{abstract}
Rafiqul Bhuyan is an assistant professor of finance at California State University, Sacramento, CA, USA. Prior to joining California State University, he was affiliated with Midwestern State University, University of Dhaka, Concordia University, North South University and Thompson River University. Dr Bhuyan has written several papers, presented papers at several international conferences in finance, and has served as a finance consultant. He holds a PhD degree in economics from Concordia University, Canada, and an MSc in finance from the University of Illinois at Urbana-Champaign, USA. Dr Bhuyan's research interests are options and futures, information economics and empirical finance.
\end{abstract}

Mo Chaudhury PhD, is a faculty lecturer in finance at McGill University, Canada. He was Principal Economist, Single Family Portfolio Management at the US mortgage giant Freddie Mac; Associate Professor of Finance, University of Saskatchewan, Canada; and had visiting appointments at McGill University, Canada, and Southern Methodist University, USA. He has taught in various international and executive programmes in Canada, Japan and China, and his research - primarily in the area of derivatives - has appeared in various reputable journals.

\section{Practical applications}

This research designs and then empirically tests trading strategies based on information implicit in the distribution of open interests across various strike prices of equity call and put options. The results suggest that the open-interest based trading strategies have the potential to generate enhanced trading returns or lower trading losses. Accordingly, investors should watch for information implicit not just in option prices but also in option market activity.

\section{Abstract}

This paper uses daily closing data on Chicago Board of Options Exchange (CBOE) options of 30 stocks during February to July, 1999, to investigate whether options open interest contains information that can be used for trading purposes. Individual stock price at option maturity is first predicted based on the distribution of options open interest. Several stock only and stock plus options directional trading strategies are then considered after comparing the predicted stock price at maturity and the actual stock price at the trade initiation date. In the sample, these trading strategies generate better returns compared with the SEP500, the buy and hold strategy involving the sample stocks
Derivatives Use, Trading \& Regulation Vol. 11 No. 1, 2005, pp. 16-36 (C) Henry Stewart Publications, $1747-4426$ 
and the Merton et al. (1978, 'The Returns and Risk of Alternative Call Option Portfolio Investment Strategies', Journal of Business, Vol. 51, pp. 183-242) style covered call strategy. The empirical evidence thus indicates that non-price measures of activity in the derivatives market - such as open interest contain information about the future level of the underlying asset. This lends support to prior works which suggest that derivatives cannot be considered as redundant in a market with information-related frictions. One implication is that the distribution of non-price derivatives market activity may be helpful for other purposes where the physical instead of the risk-neutral distribution of the underlying asset is needed. These include beta estimation, volatility forecasting and volatility trading.

\section{INTRODUCTION}

Derivative securities are considered as additional means for informed traders to trade on their information and for others to discover that information. Derivatives may not only lead the underlying assets in imparting information, they may also provide information that simply cannot be inferred from the markets in underlying assets. This paper examines the role of options market open interest in conveying information about the future movement of the underlying asset. This study shows that the activity in the equity options market seems to contain information about future stock price that can be exploited for trading purposes. Financial economists have long been interested in the process of price formation when informed traders, uninformed liquidity (or noise) traders and market makers interact in the asset market. In an asymmetric information environment, informed traders may profit at the cost of noise or liquidity traders' losses. ${ }^{1}$ Continued trading by the informed investors can, however, serve as a signal to the other (uninformed) market participants who can learn the underlying information in a Bayesian fashion and trade accordingly. ${ }^{2-4}$ Although the implications for the price paths, volume changes and trading strategies are different, information-motivated trading may also be driven by differential information $^{5}$ or differential interpretation of the same information ${ }^{6}$ by informed traders.

With the introduction of the options market, informed traders as well as liquidity traders have an additional means of meeting their trading needs. In fact, informed traders may find the options market more lucrative than the stock market, owing to lower transaction costs, lesser capital outlay, higher leverage, limited loss potential and fewer trading restrictions, (eg no up tick rule for shorting). ${ }^{7}$

If informed traders do choose to trade in the options market, not only do option prices and options market activity become relevant in imparting the information and its subsequent discovery, options could, in fact, lead the underlying stock in terms of price change and trading activity. Grossman ${ }^{8}$ suggests that underasymmetric information traded derivatives are not the same as their synthetic counterparts owing to their differential information content. While Detemple and Selden ${ }^{9}$ argue that information asymmetry may alter the hedging opportunities and, as such, affect the underlying asset price, Back et al. ${ }^{10}$ 
examine the impact on option prices. Biais and Hillion ${ }^{11}$ show that the price volatility of the underlying asset may be affected by information asymmetry. Brennan and $\mathrm{CaO}^{12}$, by contrast, show that in a noisy rational expectations equilibrium, option trades may not be information based. An impressive literature has emerged researching this and other related issues, although the empirical evidence appears inconclusive. Using the Black-Scholes model, Manaster and Rendleman ${ }^{13}$ find support for the incremental information content of options based on returns from ex post and ex ante trading strategies. Using the Berkley transaction data on options, Bhattacharya ${ }^{14}$ also finds incremental information content of options, although the trading benefits seem marginal. Vijh ${ }^{15}$ questions the ex post results based on daily closing prices owing to the bias arising from the non-synchronicity of closing stock and option trades and the bid-ask bounce. Anthony ${ }^{16}$ uses volumes of options bracketing the daily closing price and finds that, for 64 per cent of the sample stocks, the options volume led the stock volume in a Granger Causality sense. About 48 per cent of cases, however, are statistically significant in both univariate and multivariate causality tests. Stephan and Whaley ${ }^{17}$, by contrast, find stocks to lead their options in terms of both intra-day price change and trading activity. Sheikh and Ronn ${ }^{18}$ attribute unique patterns of returns in the options market to information-based trading there. John et al. ${ }^{19,20}$ show that the impact of options trading depends on the margin and liquidity constraints faced by the informed and uninformed or liquidity traders. Mayhew et al. ${ }^{21}$ find that a reduced equity options writing margin increases the bid-ask spread of the optioned stocks and that the uninformed traders are more liquidity constrained than the informed traders.

While much attention has been paid to the information content of derivative prices, theoretical research on the information content of derivatives market activity about the future movement of the underlying asset is only beginning to emerge. The general equilibrium analysis of Leisen and $\mathrm{Judd}^{22}$ provides insights into how open interests are determined along with the option prices for various strikes in an incomplete market setting. In their paper, agents have heterogeneous risk preferences but homogeneous probability beliefs about the underlying assets. As such, derivatives market activity (the distribution of open interests) is not informative about the future of the risky asset. This line of research is mainly due to Easley et al. ${ }^{23}$ In their empirical study of 50 stocks with the most actively traded options on the Chicago Board of Option Exchange (CBOE) during October and November of 1990, Easley et al. ${ }^{23}$ find that the volume of directional option trades indeed leads the stock price changes, although the total option volume has no such predictive power. This shows that the pattern of derivatives market activity may contain information about the future movement of the underlying asset.

The contribution of this paper can be summarised as follows. First, this study examines the information content of the distribution of options open interest. It uses the discrete distribution of equity option 
open interest across various strike prices as a proxy for the true or physical distribution of the stock price at option maturity. Since open interest reflects the accumulated open positions of variously informed traders, this method empirically generalises the trading set-up from information about one or two moments to consensus belief about the entire distribution of the asset.

Secondly, the information implied from derivative prices is about the risk-neutral distribution of the underlying asset. This information is certainly useful in many ways (such as hedging, pricing other derivatives of the same asset, identification of misvaluation, etc). In many other applications (eg portfolio optimisation and performance evaluation, estimation of beta or other higher order measures of risk, estimation of cost of capital, etc), however, it is the true or physical distribution of the asset that is of interest. Since only a single price of the asset is observed at a time (or the bid-ask), traditionally researchers and practitioners use some form of time series data on the asset to estimate its physical distribution. It is to be noted that converting the implied risk-neutral distribution into a physical distribution generally requires preference specification.

Thirdly, for traders who decide not to engage in private information acquisition, this study offers a new set of profitable trading strategies which rely on learning (almost free of cost) from the derivatives market (and not prices). The profitability, of course, depends on the informed traders' deciding to trade in the derivatives market. Recent research lends support to such behaviour of informed traders. Further, unlike Easley et al. ${ }^{23}$ or John et al., ${ }^{20}$ the trading strategies in the present study allow a choice of strike price for option trading. This seems more appropriate if informed investors and learner investors are wealth constrained and seek to enhance expected return from trade.

The rest of the paper is organised as follows. The next section presents the model for open interest-based stock price predictor. This is followed by a description of the data and the methodology. The third section outlines the various trading strategies and the associated pay-off patterns for the hypothetical learner investor. The empirical evidence on the comparative performance of the various passive and active strategies are then presented. The summary and conclusions are drawn in the final section.

\section{DEVELOPING STOCK PRICE AT MATURITY}

From trading over time since their introduction, open interests accumulate in call and put options of various strikes maturing in a given month. These open interests seem to leave investors expectant about the probable closing stock price for the maturity date. In this paper, the distribution of the open interests is considered to develop the predictor. Consider an optionable stock, for which there is a set of call and put options maturing at $T$, the current time being $T_{0}$. Let the price of the stock at time $t$ be $S_{t}$. Let $\left\{X_{i}, i=1,2, \ldots, K\right\}$ be the set of strike prices for call options and $\left\{X_{l}, l=1\right.$, $2, \ldots, L\}$ be the set of strike prices for put 
options. The pay-off at maturity to the buyer of a call option with a strike price $X_{i}$ is $\Pi_{i}^{c}=\operatorname{Max}\left[0, S_{T}-X_{i}\right]$. For a strike price $X_{l}$, the put option buyer's pay-off at maturity is $\Pi_{l}^{\mathrm{p}}=\operatorname{Max}\left[0, X_{l}-S_{T}\right]$. For any $t \in\left[T_{0}, T\right]$, let $O_{i t}^{c}$ be the open interest at time $t$ of call options with the strike price $X_{i}$ and, similarly, let $O_{l t}^{\mathrm{p}}$ be the time $t$ open interest at strike price $X_{l}$ for put options.

This paper proposes, by conjecture and not by proof, that the distribution of open interests at time $t$ over the range of tradable strike prices for options maturing at $T$ be used as a proxy for the consensus physical distribution of $S_{T}$, the stock price at maturity. Define a call option-open interests-based predictor (COP) by

$$
S_{t}^{\mathrm{C}} \equiv \sum_{i=1}^{K} X_{i} q_{i t}
$$

where

$$
q_{i t}=\frac{O_{i t}^{\mathrm{C}}}{\sum_{i=1}^{K} O_{i t}^{\mathrm{C}}}
$$

The weight $q_{i t}$ attached to a given strike price $X_{i}$ of a call option is the open interest of that strike price relative to the aggregate open interest of all call options at time $t$. Since these weights are, by definition, between 0 and 1.0 and sum to 1.0, they can be construed as probabilities. In a similar vein, a put option-open interest-based predictor, $S_{t}^{\mathrm{P}}$, is defined as

$$
S_{t}^{\mathrm{P}} \equiv \sum_{l=1}^{L} X_{l} q_{l t}
$$

where

$$
q_{l t}=\frac{O_{l t}^{P}}{\sum_{l=1}^{L} O_{l t}^{P}}
$$

The weight $q_{l t}$ attached to a given strike $X_{l}$ of a put option is the net open interest of that strike price relative to the aggregate net open interest of all put options at time $t$. Since financial markets may not be complete and information-related imperfections may be prevalent, a put option and a call option with similar terms may not be the mirror image of each other. Hence, open interests of both put options and call options may convey information about the terminal stock price. Accordingly, a third predictor, combined weighted average open interest based predictor (CWOP), is derived, combining the open interests of both call and put options

$$
S_{t}^{Z} \equiv \frac{\sum_{i=1}^{k} \mathrm{O}_{i t}^{\mathrm{c}} X_{t}+\sum_{l=1}^{L} \mathrm{O}_{l t}^{\mathrm{p}} X_{l}}{\sum_{i=1}^{k} \mathrm{O}_{i t}^{\mathrm{c}}+\sum_{l=1}^{L} \mathrm{O}_{l t}^{\mathrm{p}}}
$$

This combined predictor should be considered as the expected equilibrium stock price $E\left(S_{T}\right)$, as it reflects information from both call and put options markets together.

\section{DATA AND METHODOLOGY}

\section{Data}

The daily closing call and put options data (price and open interest by strike) used in this study were collected from the Dreyfus Brokerage Services (DBS). These quotes are derived from the Market Data Report of the CBOE. The data are also verified by PC Quotes. The sample period spans the six consecutive option months of February-July, 1999. An option month is 
defined as the period between the two consecutive option expiration dates. For example, the February option month extends from the first day of trading after the options expiration date in January to the last day of trading $T$ before the options expiration date in February. The options expiration date in any calendar month is usually the third Friday of that month. In case the third Friday is a holiday, the last trading day before expiration is used as the last day of the option month.

The sample consists of 30 popularly held companies chosen from the Nasdaq and the New York Stock Exchange (NYSE). A list of these companies and the sectors that they represent are provided in Table 1 . These companies were selected to represent major market indexes, a cross-section of important sectors and active options trading on the CBOE. Table 2 gives some statistical information about the sample firms, such as the market capitalisation, shares outstanding, average daily trading volume and market beta. Betas ranging from 0.70 (DuPont) to 2.59 (Applied Materials) show ample variation in market risk across the sample firms. In terms of market capitalisation, firm size ranges from $\$ 5.93$ bn (Altera) to $\$ 359.40$ bn (General Electric).

\section{Methodology}

For all strategies, positions are established using the closing prices of a trade initiation on day $t$ within an option month, and the positions are liquidated using the closing prices on the last day of trading $T$ during the option month. Options that are permissible for trading have less than 30 calendar days to expiration. Within an option month, trades may be initiated on four trading days: the second Monday (2M); the second Friday (2F); the Friday before the expiration Friday (LF); and the last Monday, ie the Monday of the expiration week (EXM). As is customary if a Monday is a holiday, trading is initiated using the closing prices of the next available trading day. Similarly, if Friday is a holiday, positions are liquidated using the closing prices of the immediately preceding trading day available. Thus, the corresponding holding periods in terms of calendar days are about 20 days (2M), 14 days (2F), 7 days (LF) and 4 days (EXM).

Short (less than a month) holding periods were chosen for this study, since information nowadays circulates quite rapidly owing to the explosive growth of internet use - especially among the investing population. As such, learning has become easier and faster and information-based trading is expected to impart information to prices without significant delays. Also, active traders tend to have a short horizon. The $2 \mathrm{M}$ trade initiation day is chosen to allow about a week of option trading during the option month following the last expiration, so it allows a week for active trades to learn or digest the option market activity information. The $2 \mathrm{~F}$ is midway through the option month, while the LF allows the option market activity to start reflecting the trades of informed traders based on the large amount of macro, industry and company statistics that are typically compiled around the turn of the month. Lastly, the EXM trade initiation day is 
Table 1: Sample firms ${ }^{a}$

\begin{tabular}{|c|c|c|c|}
\hline Symbol & Name of company & Sector & Index \\
\hline CTL & Century Telecommunications, & Services (Communication) & S\&P500 \\
\hline $\mathrm{C}$ & Inc Citigroup Inc. & Services (Bank) & DJIA \\
\hline $\mathrm{DD}$ & E.I. Dupont De Nemours & Basic Materials & DJIA \\
\hline GE & General Electric Company & Conglomerates & DJIA \\
\hline SUNW & Sun Micro Systems Inc. & Technology (HW) & Nasdaq-100 \\
\hline KO & Coca-Cola Company & Consumer (NC) & DJIA \\
\hline PG & Proctor and Gamble Co. & Consumer (NC) & DJIA \\
\hline WMT & Wall-Mart Stores, Inc. & Services (Retail) & DJIA \\
\hline $\mathrm{ABX}$ & Barrick Gold Corp. & Basic Material & S\&P500 \\
\hline AMAT & Applied Materials & Technology (Semi Eq) & Nasdaq-100 \\
\hline AMGN & Amgen, Inc. & Healthcare (Drugs) & Nasdaq-100 \\
\hline AMR & American Airlines, Inc. & Services (Transport) & DJTA \\
\hline ASND & Ascend Communications & Technology (Network) & NASDQ Comp. \\
\hline $\mathrm{CMB}$ & Chase Manhattan Corp. & Services (Bank) & S\&P500 \\
\hline COMS & 3Com Corporation & Technology (Network) & Nasdaq Comp. \\
\hline CPQ & Compaq Computer Corp. & Technology (HW) & S\&P500 \\
\hline DAL & Delta Airlines, Inc. & Services (Transport) & DJTA \\
\hline DIS & Walt Disney Company & Services (Recreation) & DJIA \\
\hline UTX & United Technologies & Conglomerates & DJIA \\
\hline $\mathrm{CSCO}$ & Cisco Systems, Inc. & Technology (Network) & Nasdaq-100 \\
\hline WCOM & MCI Worldcom, Inc. & Services (Comm.) & Nasdaq-100 \\
\hline DELL & Dell Computer Corporation & Technology (HW) & Nasdaq-100 \\
\hline SLB & Schlumberger Limited & Energy (Oil \& Equip) & S\&P500 \\
\hline ORCL & Oracle Corporation & Technology (Software) & Nasdaq-100 \\
\hline MU & Micron Technology, Inc. & Technology (Semicon) & S\&P500 \\
\hline MOT & Motorola, Inc. & Technology (Comm.E) & S\&P500 \\
\hline $\mathrm{MO}$ & Philip Morris Companies & Consumer (NC Tob) & DJIA \\
\hline ALTR & Altera Corp. & Technology (Semi. EQ) & Nasdaq Comp \\
\hline MCD & McDonald's Corporation & Services (Food) & DJIA \\
\hline S & Sears, Inc. & Services (Retail) & DJIA \\
\hline
\end{tabular}

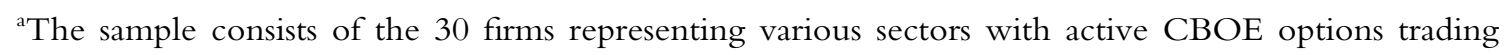
during February to July 1999. For each stock, the table gives the stock trading ticker symbol, the sector it represents on the $\mathrm{CBOE}$ and the major index in which it was included at the time. 
Table 2: Sample firms and market statistics: market beta, market capitalisation, shares floating, shares outstanding and average daily volumes of trade for each selected firm

\begin{tabular}{|c|c|c|c|c|c|}
\hline Symbol & Beta & $\begin{array}{l}\text { Market } \\
\text { capitalisation } \\
\text { (billions) }\end{array}$ & $\begin{array}{l}\text { Shares floating } \\
\text { (millions) }\end{array}$ & $\begin{array}{l}\text { Shares } \\
\text { outstanding } \\
\text { (millions) }\end{array}$ & $\begin{array}{l}\text { Daily volume } \\
\text { (millions) }\end{array}$ \\
\hline CTL & 0.96 & 6.72 & 60.00 & 92.40 & 0.31 \\
\hline $\mathrm{C}$ & 1.41 & 146.10 & 2190.00 & 2260.00 & 9.11 \\
\hline $\mathrm{DD}$ & 0.70 & 64.00 & 1010.00 & 1300.00 & 2.99 \\
\hline GE & 1.14 & 359.40 & 3200.00 & 3270.00 & 4.58 \\
\hline SUNW & 1.42 & 43.90 & 373.70 & 385.30 & 7.68 \\
\hline $\mathrm{KO}$ & 1.02 & 168.30 & 2000.00 & 2470.00 & 3.72 \\
\hline PG & 0.93 & 123.10 & 1310.00 & 1330.00 & 2.19 \\
\hline WMT & 0.88 & 218.30 & 1180.00 & 2220.00 & 3.10 \\
\hline $\mathrm{ABX}$ & 1.12 & 6.84 & 300.80 & 376.00 & 1.31 \\
\hline AMAT & 2.59 & 23.80 & 369.20 & 373.00 & 8.82 \\
\hline AMGN & 1.16 & 39.70 & 498.80 & 509.00 & 4.78 \\
\hline AMR & 1.22 & 11.30 & 169.60 & 182.30 & 1.64 \\
\hline ASND & 1.62 & 17.00 & 190.90 & 216.90 & 2.41 \\
\hline $\mathrm{CMB}$ & 1.41 & 70.80 & 835.80 & 844.20 & 4.08 \\
\hline COMS & 1.78 & 8.95 & 340.00 & 358.80 & 9.45 \\
\hline CPQ & 1.36 & 54.20 & 1670.00 & 1700.00 & 16.00 \\
\hline DAL & 0.87 & 10.00 & 102.00 & 141.60 & 1.17 \\
\hline DIS & 0.93 & 72.90 & 2010.00 & 2060.00 & 6.21 \\
\hline UTX & 1.26 & 29.70 & 184.60 & 225.10 & 0.71 \\
\hline $\mathrm{CSCO}$ & 1.35 & 170.70 & 1570.00 & 1600.00 & 15.50 \\
\hline WCOM & 1.48 & 171.90 & 1710.00 & 1830.00 & 11.60 \\
\hline DELL & 1.70 & 107.50 & 1960.00 & 2540.00 & 44.20 \\
\hline SLB & 1.05 & 32.30 & 519.00 & 546.40 & 3.26 \\
\hline ORCL & 1.45 & 42.70 & 1090.00 & 1440.00 & 15.60 \\
\hline MU & 2.39 & 12.90 & 101.50 & 247.70 & 5.13 \\
\hline MOT & 1.20 & 43.60 & 576.20 & 600.20 & 3.04 \\
\hline MO & 0.73 & 101.90 & 2230.00 & 2430.00 & 7.24 \\
\hline ALTR & 1.99 & 5.93 & 80.80 & 97.30 & 2.44 \\
\hline MCD & 0.96 & 59.90 & 1340.00 & 1360.00 & 3.78 \\
\hline S & 1.05 & 341.30 & 341.30 & 383.50 & 1.43 \\
\hline
\end{tabular}


included to pick up any information-based peculiarity of the weekend before expiration or potential last-minute strategic trading moves by the market participants.

A sum of around $\$ 10,000$ is allowed to be invested in a given stock and/or its options on a given trade initiation day. Since an option contract is for 100 shares, some rounding was necessary (to be discussed later) to determine the number of contracts and shares that could be traded.

As a result, the investment sum $I$ for a stock could be different from $\$ 10,000$ in some strategies involving stock and options. Once the positions are established based on the distribution of open interests and using the closing stock and option prices for trade implementation, they are held until the end of the option month. It is assumed that investors are not allowed to borrow securities on margin. The risk-free interest rate is assumed to be zero, as the interest up to three weeks is inconsequential.

Under each strategy, for each stock, first, the dollar profit or return $\Pi$ is estimated using the closing stock and option prices on the trade initiation day and the option maturity date. In calculating the dollar return, a zero transaction cost is assumed for stock trading, $\$ 30$ for one-way option trading and zero transaction cost for option exercises. Secondly, for each stock, the holding period percentage return on investment (PROI) for the strategy is calculated based on the dollar return and the estimated investment (around $\$ 10,000$ ). The performance of a strategy is then measured as the (cross-sectional) average of the percentage return on investment with respect to the 30 sample stocks. Whenever possible and appropriate, the cross-sectional standard deviation of PROI is also presented as a proxy for the risk or volatility of returns on a strategy.

Further, for a small number of stocks, there were major news events after the trade initiation day (prior to the next option expiration date) during the sample period. Following these events, the stock price often moved significantly and seemingly against recent stock trend. When this happens, the expiration day actual stock price may end up being widely different from the open interest based predictor. If, prior to the news event, the stock was trending up and the open interest-based predictor was also signalling an upward move, it is more reasonable to assume that any negative information pertaining to the news event came as a surprise to all investors.

To see the impact of these news shocks on the relative performance of the active strategies, two sets of results were estimated for the open interest-based active strategies. One set of results assumes that the hypothetical investor did not know that news shocks were coming for some of the stocks and hence established positions in all 30 stocks using the pre-news open interest-based predictor and the pre-news closing prices on trade initiation day. This portfolio is called the ignore news (IN) portfolio. The second set of results assumes that the hypothetical learner investor had guessed correctly the stocks for which the news shocks were coming. The investor, however, did not know the nature (positive or negative) of the news shocks. Since the investor is restricted to directional trading 
only, in the second set of results it is assumed that the hypothetical investor did not establish positions with respect to the stocks on the trade initiation day. The performance of an active strategy in this case is the average PROI on the positions with respect to the remaining non-event stocks. This portfolio is referred to as the consider news $(\mathrm{CN})$ portfolio. Of course, one would expect the PROI to be higher for the $\mathrm{CN}$ portfolio.

\section{TRADING STRATEGIES AND RETURNS}

This section delineates the specifics of the trading strategies with respect to a given stock that the hypothetical learner investor may follow. These strategies are, respectively, the passive buy-and-hold (stock only) strategy; Merton et al.-type ${ }^{24}$ covered call (stock plus option) strategies; open interest-based active strategy using only stock; and open interest-based limited risk active strategies using stock plus options.

\section{Passive buy and hold strategy (stock only)}

For a given stock, the buy-and-hold strategy simply involves buying shares at the closing price of the trade initiation day. The expected dollar return for the buy-and-hold strategy for a stock is

$$
\begin{aligned}
\Pi_{\mathrm{BH}} & =\left[\left(S_{T}-S_{t}\right) \times N_{s}\right]-I \\
N_{s} & =10,000 / S_{t}
\end{aligned}
$$

where $S_{T}$ is the closing stock price at the option maturity date, $S_{t}$ is the closing stock price on the trade initiation day, $N_{s}$ is the number of shares bought, and $I$ is the net outlay. Here, $I=S_{t} \times N_{\mathrm{s}} \cong 10,000$. The PROI is estimated as follows

$$
\operatorname{PROI}_{\mathrm{BH}}=\left(\Pi_{\mathrm{BH}} \div I\right) \times 100
$$

An equally weighted portfolio of all 30 stocks is then formed. This portfolio is called the naïve investor (NI) portfolio. The holding period return on this portfolio is simply the average return on the 30 stocks from the specific trade initiation day to the end of the option month.

\section{Merton et al. (passive) covered call strategy}

A covered call strategy differs from a buy-and-hold strategy in that the dollar loss on the stock is reduced by the option premium received and the dollar gains on the stock are capped by the strike price (if the written call is out-of-the-money when the position is initiated). Thus, ex ante, compared with the buy-and-hold strategy, the covered call strategy has lower return potential and less volatility. This ex ante comparative performance of covered call strategy was confirmed by Merton et al. $\mathrm{s}^{24}$ simulation results for two different stock samples over the July 1963 to December 1975 period. Their (passive) covered call strategy is included, as it provides a benchmark for the active strategies involving stock plus options. Merton et al. do not provide any objective guidance for the selection of the written call's strike price. In contrast, in the active strategies to be discussed later in this paper, the hypothetical investor selects a specific moneyness or strike price for written call 
options based on the open-interest based stock price predictor.

For the Merton et al.-type passive covered call strategy, on a trade initiation day the hypothetical investor buys approximately $\$ 10,000$ worth of each stock and receives premiums from selling or shorting call options on the shares that expire at the end of the option month. The investor is restricted to writing call options all of the same moneyness, defined as percentage deviation from the initial stock price. These can be either all out-of-the-money, all at-the-money (or nearest-to-the-money), or all in-the-money call options. Since the observed strike prices are set at discrete intervals, strike prices are chosen for the individual stocks to maintain roughly the same level of moneyness. The dollar return for the at-the-money covered call strategy is given by the following equation

$$
\begin{aligned}
\Pi_{\mathrm{CC}}= & \left\{\left(S_{T}-S_{t}\right) \times N_{\mathrm{S}}+\left[\left(C_{i t} \times N_{\mathrm{C}}\right)\right.\right. \\
& \left.\times 100-T_{\mathrm{C}}\right]-\left[\operatorname { m a x } \left(0,\left(S_{T}-X_{i}\right)\right.\right. \\
& \left.\left.\left.\times N_{\mathrm{C}}\right)\right](\times 100)\right\}
\end{aligned}
$$

where $C_{i t}$ is the closing price of the call option with strike $X_{i}$ on the trade initiation day, $T_{\mathrm{C}}$ is the total transaction cost for the call option transactions, and $N_{\mathrm{S}} / 100=N_{\mathrm{C}}$ is the number of call option contracts written and is equal to $\$ 10,000 / S_{t}$ rounded to the nearest integer. Since option trades incur a fixed ordering cost plus a per contract transaction cost, $T_{\mathrm{C}}$ can be significant, percentage-wise, for orders of small value. The initial investment required on a fully covered position $I_{\mathrm{CC}}$ is given by

$$
I_{\mathrm{CC}}=N_{\mathrm{S}} \times S_{t}-\left(C_{i t} \times N_{\mathrm{C}}\right) * 100
$$

Three different equally weighted portfolios are formed using the covered call positions of the 30 individual stocks. These portfolios are named OMP (out-of-the-money calls written), AMP (at-the-money or nearest-to-the-money calls written) and IMP (in-the-money calls written). The portfolio return is just the average return on the 30 individual stocks' covered call positions.

\section{Open interest-based active strategy (stock only)}

At the close of a trade initiation day $t$, the active investor estimates the expected terminal stock price $S_{t}^{Z}$, based on the distribution of open interests of call and put options of various strike prices but all maturing at the same date $T$. If the predictor $S_{t}^{Z}$ is greater (smaller) than the contemporary security price $S_{t}$, the investor considers this a buy (sell) signal and goes long (short) on the stock. The expected dollar returns and the percentage returns for the active long stock strategy are as in equations (4) and (5). The expected dollar returns for the active short stock strategy are given by the following equation

$$
\Pi_{\mathrm{AS}}=\left[S_{t i}-S_{T i}\right] \times N_{\mathrm{S}}-I
$$

\section{Open interest-based active strategy (stock plus options)}

The open interest-based active stock strategy can be quite risky for individual stocks. Therefore, limited risk active strategies involving stocks and options are considered. As in the active stock strategy, on each trade initiation day $t$, the investor compares the actual closing stock price $S_{t}$ 
and the open interest-based price predictor $S_{t}^{\mathrm{Z}}$. Here, however, the investor considers the magnitude as well as the direction of the predicted price movement. The magnitude is considered a major move if $S_{t}^{Z}$ either goes past or at least is closer to the next available strike in the direction of the price move than it is to the current stock price $S_{t}$. By and large, this meant a change of more than five per cent in the sample. Minor moves mostly meant a change of less than two per cent in the sample. According to the direction and the magnitude of the predicted stock price movement, one has the following four cases.

\section{ASP1: Price predictor signals a minor upward movement in the stock}

If the price predictor indicates a minor upside for a stock, the investor buys the stock at the closing market price on the trade initiation day and writes a call option. The strike price of the written call option is chosen based on the upside potential indicated by the price predictor and the availability of strike prices. The dollar return and initial investment for the strategy ASP1 are given by the following equations

$$
\begin{aligned}
\Pi_{\mathrm{ASPI}}= & {\left[\left(S_{T}-S_{t}\right) \times N_{\mathrm{S}}\right.} \\
& +\left(C_{x i} \times N_{\mathrm{C}}-T_{\mathrm{C}}\right) \\
& \times 100-\max \left\{0,\left(S_{T}-X_{i}\right)\right. \\
& \left.\left.\times N_{\mathrm{C}}\right\} \times 100\right]-I_{\mathrm{ASPI}}
\end{aligned}
$$

where $X_{t} \cong S_{t}^{Z}$. Here the symbol $\cong$ means closest to $S_{t}^{Z}$ in the direction of the predicted price movement.

$$
I_{\mathrm{ASPI}}=N_{\mathrm{S}} \times S_{t}-\left(C_{\mathrm{X} i} \times N_{\mathrm{C}}\right) \times 100
$$

In the equations above, $N_{\mathrm{S}}=N_{\mathrm{C}} \times 100$ is the number of shares that can be purchased with $\$ 10,000$, rounded to the nearest 100 .

\section{ASP2: Price predictor signals a major upward movement in the stock}

If the price predictor indicates a major upside for a stock, as in strategy ASP1, the investor pursues a limited risk active covered call strategy. The investor buys the stock at the closing market price on the trade initiation day and sells a deep-out-of-the-money (significantly higher strike) call option; the strike is chosen based on the upside potential indicated by the price predictor and the availability of strike prices. The dollar return and the initial investment return on ASP2 are then estimated as

$$
\begin{aligned}
\Pi_{\mathrm{ASP} 2}= & \left\{\left(S_{T}-S_{t}\right) \times N_{\mathrm{S}}+\max \left[\left(S_{T}-X_{Y i}\right)\right.\right. \\
& \left.\times N_{\mathrm{C}}, 0\right] \times 100-\left[\left(C_{\gamma i} \times N_{\mathrm{C}}\right)\right. \\
& \left.\times 100+T_{\mathrm{C}}\right]+\left[\left(C_{\gamma y i} \times N_{\mathrm{C}}\right)\right. \\
& \left.\times 100-T_{\mathrm{C}}\right]-\max \left[\left(S_{T}-X_{y \gamma i}\right)\right. \\
& \left.\left.\times N_{\mathrm{C}}, 0\right] \times 100\right\} \\
X_{\gamma i} \cong S_{t} ; & X_{y \gamma i} \approx S_{t}^{\mathrm{Z}} \\
I_{\mathrm{ASP} 2}= & N_{\mathrm{S}} \times S_{t}+\left(C_{Y i} \times N_{\mathrm{C}}\right) \times 100 \\
& -\left(C_{\gamma y i} \times N_{\mathrm{C}}\right) \times 100
\end{aligned}
$$

If the premium for the deep-out-of-the-money call is too low relative to transaction cost or the contract has no volume, an equal number of shares and at-the-money call options are bought instead for a total sum of $\$ 10,000$. The purchase of at-the-money call options partially to replace the purchase of shares then makes the ASP2 strategy more bullish 
(more leveraged) than when the deep-out-of-the-money option premium exceeds the options transaction cost. The number of such cases is rather small, however, and has no material impact on the overall (portfolio) returns of the strategy ASP2. Hence, for ASP2, the authors shall pretend from hereon that the option premium received is large enough to handily offset the transaction cost.

\section{ASP3: Price predictor signals a minor downward movement in the stock}

If the price predictor indicates a minor downside for a stock, the investor writes a covered call at a strike near the closing stock price on the trade initiation day. The dollar returns and the initial investment for the strategy ASP3 are given by the following equations

$$
\begin{aligned}
\Pi_{\mathrm{ASP} 3}= & \left\{\left(S_{T}-S_{t}\right) \times N_{S}\right. \\
& -\left[\left(\max \left\{X_{V i}-S_{T}\right) \times N_{\mathrm{C}}, 0\right\}\right. \\
& \times 100)+\left(C_{V i} \times N_{C}\right) \\
& \left.\left.\times 100-T_{\mathrm{C}}\right]\right\}
\end{aligned}
$$

$$
\begin{aligned}
& X_{V i}=\text { call strike closed to } S_{t} \\
& I_{\mathrm{ASP} 3}=N_{\mathrm{S}} \times S_{t}-\left(C_{V i} \times N_{\mathrm{C}}\right) \times 100
\end{aligned}
$$

In the above equations, $C_{V i}$ is the price of the call contract with strike $X_{V i}$. The transaction costs are $T_{\mathrm{C}}$ for $N_{\mathrm{C}}$ call option contracts written and $N_{\mathrm{C}}=N_{\mathrm{S}} / 100$, where $N_{\mathrm{S}}$ is $\$ 10,000 / S_{t}$ rounded to the nearest 100 .

\section{ASP4: Price predictor signals a major downward movement in the stock}

If the price predictor indicates a major downside for a stock, the investor writes a covered call at a strike close to the predicted stock price at maturity and buys a put option with the strike near or above the closing stock price on the trade initiation day. The dollar returns and the initial investment for the strategy ASP4 are given by following equations

$$
\begin{aligned}
& \Pi_{\mathrm{ASP} 4}=\left\{\left(S_{T}-S_{t}\right) \times N_{\mathrm{S}}-\left[\left(P_{Z i} \times N_{P}\right)\right.\right. \\
&\left.\times 100+T_{P}\right]+\left[\operatorname { m a x } \left\{\left(X_{Z i}-S_{T}\right)\right.\right. \\
&\left.\left.\times N_{P}, 0\right\} \times 100\right] \\
&-\left[\max \left\{\left(X_{V i}-S_{T}\right) \times N_{\mathrm{C}}, 0\right\}\right. \\
&\times 100)+\left(C_{V i} \times N_{\mathrm{C}}\right) \\
&\left.\left.\times 100-T_{\mathrm{C}}\right]\right\} \\
& X_{Z i}=\text { put strike closed to } S_{t}, \text { and } \\
& X_{V i}=\text { call strike closest to } S_{t}^{Z} \\
& I_{\mathrm{ASP} 4}= N_{\mathrm{S}} \times S_{t}-\left(C_{V i} \times N_{\mathrm{C}}\right) \times 100 \\
&+\left(P_{Z i} \times N_{\mathrm{P}}\right) \times 100
\end{aligned}
$$

In the above equations, $P_{Z i}$ is the price of the put option with strike $X_{\mathrm{Zi}}$, and $C_{V i}$ is the price of the call contract with strike $X_{V i}$. The transaction costs are $T_{\mathrm{C}}$ for $N_{\mathrm{C}}$ call option contracts written and $T_{\mathrm{C}}$ for $N_{\mathrm{P}}$ put option contracts bought, and $N_{\mathrm{C}}=N_{\mathrm{P}}=N_{\mathrm{S}} / 100$, where $N_{S}$ is $\$ 10,000 / S_{t}$ rounded to the nearest 100 .

\section{EVIDENCE ON COMPARATIVE PERFORMANCE}

To obtain a sense of how the active positions are established and aggregated to arrive at portfolio results, Table 3 provides an example of detailed stock by stock prediction, strategy and performance for the stock only active strategy (AS). It shows that for the February option month of 1999 
the comparative performances of the buy and hold strategy (NI portfolio), the stock only active strategy considering news (CN or OPP portfolio) and the stock only active strategy ignoring news (IN portfolio).

The first column of Table 3 indicates the symbols of the sample stocks. The second column displays the closing prices, $S_{T}$, at the option maturity date. The third column shows the open interest-based stock price prediction $S_{t}^{Z}$, where $t$ is the second Friday of the February 1999 option month. The fourth column indicates the closing stock price $S_{t}$ on the trade initiation day $t$. The fifth column shows the direction of movement of the stock signalled or predicted by the predictor. The sixth column shows the stock only active trading strategy (BUY for long and SS for short selling) for the hypothetical learner investor. The seventh column refers to the number of shares the investor buys or sells short with $\$ 10,000$. The last three columns display the PROI for the 14 days holding period for the NI, CN (OPP) and IN portfolios.

The trade initiation day $t$ is the second Friday of the February 1999 option month that runs from the first day of trading after option expiration in January 1999 to the last day of trading $T$ before option expiration day in February 1999. Time to expiration or the holding period here is 14 calendar days. $S_{t}$ and $S_{T}$ are the actual closing prices of the stock at $t$ and $T$. $S_{t}^{Z}$ is the open interest-based prediction at $t$ for $S_{T}$.

If $S_{t}<S_{t}^{Z}$, the prediction or signal is an upward move (UP) for the stock from $t$ to $T$ and the hypothetical active investor goes long on the stock (BUY). If $S_{t}>S_{t}^{\mathrm{Z}}$, the prediction is a down move (DOWN) for the stock from $t$ to $T$, and the hypothetical active investor goes short on the stock (SS).

The results in Table 3 indicate that the hypothetical investor could have earned a return of 0.86 per cent for the two-week holding period in the February 1999 option month following the stock only active strategy and excluding the one stock (MO) that had a major news event during the holding period. If this wisdom or foresight is taken away, the return to the stock only active strategy would have been 0.39 per cent. While the impact of the news event is important, it does not change the ranking of the active strategy vis-à-vis the naïve investor's passive strategy of blindly buying the stocks and holding them. The NI strategy/portfolio provides a negative return of -0.80 per cent. Thus, the active $\mathrm{CN}$ (IN) strategy had an incremental 1.66 per cent (1.19 per cent) for the two-week holding period or about 43.16 per cent (30.94 per cent) annualised.

While Table 3 does not present any risk measure and concerns only one initiation day in one option month, it seems that the return advantage of the active strategy compared with the buy and hold strategy is quite convincing. Thus, there is a preliminary indication that options open interest contains information about future stock movement which can be used for profitable trading. The volatility of the active strategy returns relative to the volatility of the buy and hold returns have to be quite high to nullify the active strategy's attractiveness.

The option-based predictor calls for a 
Table 3: Individual stock performance of buy and hold and stock only active strategy (AS)

\begin{tabular}{|c|c|c|c|c|c|c|c|c|c|}
\hline \multirow[b]{2}{*}{$\begin{array}{l}\text { Stock } \\
\text { symbol }\end{array}$} & \multirow[b]{2}{*}{$S_{T}$} & \multirow[b]{2}{*}{$S_{t}^{Z}$} & \multirow[b]{2}{*}{$S_{t}$} & \multirow[b]{2}{*}{ Signal } & \multirow[b]{2}{*}{$\begin{array}{l}\text { Active } \\
\text { strategy }\end{array}$} & & \multicolumn{3}{|c|}{$\begin{array}{l}\text { PROI (\% return on investmen } \\
\text { Portfolio type: }\end{array}$} \\
\hline & & & & & & $N_{S}$ & $I N$ & $\begin{array}{l}C N \\
(O P P)\end{array}$ & $N I$ \\
\hline$A B X$ & 18.44 & 20.21 & 20.25 & DOWN & SS & 494.00 & 8.91 & 8.91 & -8.91 \\
\hline ALTR & 58.50 & 61.85 & 56.75 & UP & BUY & 176.00 & 2.96 & 2.96 & 2.96 \\
\hline AMAT & 68.69 & 53.42 & 60.69 & DOWN & SS & 165.00 & -13.34 & -13.34 & 13.34 \\
\hline AMGN & 124.12 & 112.20 & 119.63 & DOWN & SS & 84.00 & -4.26 & -4.26 & 4.26 \\
\hline AMR & 53.75 & 61.25 & 59.94 & UP & BUY & 167.00 & -10.24 & -10.24 & 10.24 \\
\hline ASND & 77.18 & 77.18 & 77.00 & UP & BUY & 130.00 & 0.33 & 0.33 & 0.33 \\
\hline $\mathrm{C}$ & 54.18 & 53.39 & 52.88 & UP & BUY & 189.00 & 2.40 & 2.40 & 2.40 \\
\hline $\mathrm{CMB}$ & 76.06 & 68.47 & 76.43 & DOWN & SS & 131.00 & 0.36 & 0.36 & -0.36 \\
\hline COMS & 33.18 & 47.24 & 34.19 & UP & BUY & 293.00 & -2.78 & -2.78 & -2.78 \\
\hline CPQ & 41.12 & 46.04 & 43.63 & UP & BUY & 229.00 & -5.84 & -5.84 & -5.84 \\
\hline CSCO & 97.12 & 102.95 & 101.25 & UP & BUY & 99.00 & -3.85 & -3.85 & -3.85 \\
\hline CTL & 62.32 & 66.42 & 67.38 & DOWN & SS & 149.00 & 7.14 & 7.14 & -7.14 \\
\hline DAL & 55.06 & 54.20 & 57.56 & DOWN & SS & 174.00 & 4.20 & 4.20 & -4.20 \\
\hline DD & 52.75 & 55.65 & 55.12 & UP & BUY & 182.00 & -4.00 & -4.00 & -4.00 \\
\hline DELL & 80.12 & 76.46 & 100.44 & DOWN & SS & 100.00 & 19.88 & 19.88 & -19.88 \\
\hline DIS & 34.12 & 34.28 & 34.25 & UP & BUY & 292.00 & -0.37 & -0.37 & -0.37 \\
\hline GE & 100.38 & 99.26 & 98.00 & UP & BUY & 102.00 & 2.39 & 2.39 & 2.39 \\
\hline $\mathrm{KO}$ & 65.75 & 67.12 & 62.06 & UP & BUY & 161.00 & 5.86 & 5.86 & 5.86 \\
\hline MCD & 85.56 & 78.74 & 80.31 & DOWN & SS & 125.00 & -6.95 & -6.95 & 6.95 \\
\hline MO & 39.94 & 50.07 & 46.13 & $\mathrm{UP}^{\mathrm{a}}$ & BUY & 217.00 & -13.33 & 0.00 & -13.33 \\
\hline MOT & 67.38 & 67.58 & 66.44 & UP & BUY & 151.00 & 1.74 & 1.74 & 1.74 \\
\hline MU & 64.12 & 64.47 & 70.25 & DOWN & SS & 143.00 & 8.31 & 8.31 & -8.31 \\
\hline ORCL & 54.19 & 50.76 & 56.19 & DOWN & SS & 178.00 & 3.54 & 3.54 & -3.54 \\
\hline PG & 91.82 & 89.38 & 84.88 & UP & BUY & 118.00 & 8.35 & 8.35 & 8.35 \\
\hline$S$ & 39.69 & 39.85 & 40.31 & DOWN & SS & 248.00 & 1.57 & 1.57 & -1.57 \\
\hline SLB & 49.19 & 50.42 & 53.00 & DOWN & SS & 189.00 & 7.03 & 7.03 & -7.03 \\
\hline SUNW & 96.94 & 100.19 & 100.63 & DOWN & SS & 100.00 & 3.06 & 3.06 & -3.06 \\
\hline UTX & 125.44 & 104.88 & 125.00 & DOWN & SS & 84.00 & -0.35 & -0.35 & 0.35 \\
\hline WCOM & 84.18 & 73.32 & 76.25 & DOWN & SS & 131.00 & -10.28 & -10.28 & 10.28 \\
\hline WMT & 84.75 & 80.92 & 84.25 & DOWN & SS & 119.00 & -0.85 & -0.85 & 0.85 \\
\hline Average $\mathrm{P}$ & & & & & & & 0.39 & 0.86 & -0.80 \\
\hline
\end{tabular}

${ }^{a}$ A major news event took place for the stock after the trade initiation day. 
DOWN option month in all option months except June. Of the cases in which the prediction was UP, it proved to be a correct call in 67 per cent (February), 50 per cent (March), 54 per cent (April), 55 per cent (May), 77 per cent (June) and 87 per cent (July) of cases. Of the cases in which the prediction was DOWN, it proved to be a correct call in 60 per cent (February), 45 per cent (March), 80 per cent (April), 81 per cent (May), 24 per cent (June) and 56 per cent (July) of cases. Averaging over the six option months, the accuracy of the UP prediction is 65 per cent and that of the DOWN prediction is 58 per cent. Thus, the UP predictions may appear more accurate than the DOWN predictions. But in the DOWN option months (February, April and May), when a majority of sample stocks suffered loss, the accuracy of DOWN prediction is 60 per cent, 80 per cent and 81 per cent, respectively, averaging to 74 per cent accuracy. By contrast, in the UP option months (March, June and July) when a majority of sample stocks marched higher, the accuracy of an UP prediction is 50 per cent, 77 per cent and 87 per cent, respectively, averaging to 71 per cent accuracy.

Table 4 reports the number and the percentage (in parentheses) of cases in which the sample stocks actually moved up (actual up) or down (actual down) from the four alternative trade initiation days to the option expiration day during the six option months of February to July 1999. Of the total 120 possible cases during this option month (four holding periods for each of the 30 stocks), in 49 or 41 per cent of cases, the stocks actually moved up and, in the remaining 71 or 59 per cent of cases, the stocks actually moved down.

This table also reports the number and percentage (in parentheses) of cases in which the sample stocks were predicted by the open interest-based price predictor to move up (predicted up) or down (predicted down) from the four alternative trade initiation days to the option expiration day during the six option months of February to July 1999.

Lastly, the table reports the number of cases where the prediction of upward movement (correct up) or downward movement (correct down) proved to be correct. The percentage in parentheses here represents the number of correct UP (DOWN) predictions as a percentage of the number of UP (DOWN) predictions.

Table 5 presents the comparative performance results for the various passive and active strategies in the six option months considering the four alternative trade initiation days (2F, 2M, LF, EXM) within each option month.

The table reports the percentage holding PROI for the buy and hold strategy (NI), the stock only active strategy (AS), the stock plus options limited risk active strategy (ASP) and Merton et al.-style ${ }^{24}$ covered call strategies (OMP, AMP, IMP). The PROI on S\&P500 is also reported for the corresponding holding periods. For each strategy, the first row presents the cross-sectional average and the second row (in italics) presents the cross-sectional standard deviation of PROI across the sample stocks. The S\&P500 figures are just the holding period returns and not averages 
Table 4: Prediction (up or down) performance of the open interest based price predictor

$\begin{array}{lcccccc}\text { Option month } & \text { February } & \text { March } & \text { April } & \text { May } & \text { June } & \text { July } \\ & & & & & & \\ \text { Actual up (\% of total) } & 49(41) & 64(53) & 36(30) & 42(35) & 92(77) & 76(63) \\ \text { Actual down (\%of total) } & 71(59) & 56(47) & 84(70) & 78(65) & 28(23) & 44(37) \\ \text { Predicted up (\% of total) } & 42(35) & 48(40) & 35(29) & 53(44) & 78(65) & 54(45) \\ \text { Predicted down (\%of total) } & 78(65) & 72(60) & 85(71) & 67(56) & 42(35) & 66(55) \\ \text { Correct up (\% of predicted up) } & 28(67) & 24(50) & 19(54) & 29(55) & 60(77) & 47(87) \\ \text { Correct down (\% of predicted down) } & 47(60) & 32(45) & 68(80) & 54(81) & 10(24) & 37(56)\end{array}$

across the component stocks. The PROI is not annualised.

Considering all 120 cases of prediction, a passive investor investing in the S\&P500 would have earned 1.53 per cent return on average. If the passive investor followed the equally weighted buy and hold strategy, the average return would have been 1.00 per cent. Considering that the average holding period is about 11-12 days, these returns translate to about 49 per cent annualised return for the S\&P500 and about 32 per cent annualised return for the equally weighted portfolio of the 30 blue chip sample stocks. Given that 1999 was a stellar year for stocks, these returns appear realistic.

Now consider the aggregate performance of the open interest-based stock only active strategy. Following this strategy, the hypothetical learner investor could expect to earn 9.05 per cent return on average. By any means, the return advantage of the open interest-based active strategy seems convincing. That this return advantage did not arise owing to better performance in just one or two months or for just one or two specific trade initiation days can be observed from the detailed performance numbers in Table 5. Table 5 highlights which stocks only strategy (S\&P500, NI, AS) earned the highest return in a given option month for a given trade initiation day. For example, the AS strategy had the highest return in 16 of the 24 option month/trade initiation day combinations, and these cases are well spread over the various months and trade initiation days.

For the limited risk strategies, the benchmark used for the limited risk strategies is the Merton et al.-type ${ }^{24}$ covered call strategy. In aggregate, the passive covered call strategy earns 1.96 per cent (OMP), 2.43 per cent (AMP) and 2.14 per cent (IMP). In sharp contrast, the stock plus options limited risk active strategy (ASP) earns 11.20 per cent. Looking at the standard deviations, the risk of the limited risk active strategy appears consistently lower than that of the passive out-of-the-money covered call strategy.

Overall, the comparative performance results indicate an impressive trading advantage of predictions based on the 
Table 5: Comparative performance of the passive and active strategies

\begin{tabular}{|c|c|c|c|c|c|c|c|c|}
\hline \multirow{3}{*}{$\begin{array}{l}\text { Option } \\
\text { month }\end{array}$} & \multirow{3}{*}{$\begin{array}{l}\text { Trade initiation } \\
\text { day, } t\end{array}$} & \multicolumn{3}{|c|}{ Portfolio/strategy } & \multirow{2}{*}{\multicolumn{3}{|c|}{$\begin{array}{l}\text { Portfolio/strategy } \\
\text { ASP Merton }\end{array}$}} & \multirow{3}{*}{$\begin{array}{l}\text { covered call } \\
I M P\end{array}$} \\
\hline & & & & & & & & \\
\hline & & $A S(C N)$ & $N I$ & SEP500 & $(\mathrm{CN})$ & $O M P$ & $A M P$ & \\
\hline \multirow[t]{2}{*}{ February } & $2 \mathrm{~F}$ & 8.03 & -8.06 & -0.02 & 9.46 & -1.95 & 0.64 & 2.07 \\
\hline & & 17.18 & 18.31 & & 12.34 & 13.59 & 9.73 & 4.47 \\
\hline \multirow[t]{2}{*}{ February } & $2 \mathrm{M}$ & 2.01 & -1.87 & -0.86 & 6.14 & -4.84 & 5.11 & 2.38 \\
\hline & & 17.34 & 17.79 & & 16.13 & 26.74 & 14.39 & 6.83 \\
\hline \multirow[t]{2}{*}{ February } & $\mathrm{LF}$ & 9.87 & -7.70 & 2.56 & 7.74 & -4.80 & -2.27 & 2.59 \\
\hline & & 25.44 & 27.96 & & 14.87 & 21.47 & 11.98 & 7.34 \\
\hline \multirow[t]{2}{*}{ February } & EXM & 1.79 & 4.09 & -1.18 & 4.65 & 6.22 & 4.47 & 3.13 \\
\hline & & 24.02 & 23.80 & & 17.70 & 24.25 & 15.01 & 10.14 \\
\hline \multirow[t]{2}{*}{ March } & $2 \mathrm{~F}$ & 9.40 & 7.01 & 3.86 & 9.42 & 1.42 & 0.13 & -0.98 \\
\hline & & 21.22 & 23.93 & & 14.49 & 15.13 & 11.10 & 7.87 \\
\hline \multirow[t]{2}{*}{ March } & $2 \mathrm{M}$ & -0.39 & 1.96 & 3.33 & 5.06 & 6.22 & 3.42 & -0.26 \\
\hline & & 15.42 & 20.96 & & 15.11 & 19.42 & 11.95 & 10.09 \\
\hline \multirow[t]{2}{*}{ March } & $\mathrm{LF}$ & -3.53 & -0.04 & 1.40 & 5.31 & 1.32 & 3.50 & 2.57 \\
\hline & & 14.88 & 17.14 & & 14.53 & 20.39 & 12.87 & 7.35 \\
\hline \multirow[t]{2}{*}{ March } & EXM & 0.99 & -5.08 & -3.78 & -0.12 & -1.41 & -0.18 & -1.37 \\
\hline & & 21.70 & 22.82 & & 17.48 & 22.75 & 18.22 & 15.55 \\
\hline \multirow[t]{2}{*}{ April } & $2 \mathrm{~F}$ & 5.99 & -2.40 & 4.03 & 9.94 & -3.98 & -1.27 & 1.78 \\
\hline & & 20.65 & 27.63 & & 15.23 & 21.18 & 13.02 & 6.42 \\
\hline \multirow[t]{2}{*}{ April } & $2 \mathrm{M}$ & 15.84 & -7.10 & -0.41 & 11.91 & -4.07 & -1.59 & 1.59 \\
\hline & & 18.80 & 22.08 & & 20.76 & 28.36 & 20.89 & 6.93 \\
\hline \multirow[t]{2}{*}{ April } & $\mathrm{LF}$ & 12.09 & -14.07 & -8.45 & 12.32 & -13.47 & -5.44 & 2.00 \\
\hline & & 33.00 & 40.07 & & 22.79 & 31.47 & 15.56 & 8.24 \\
\hline \multirow[t]{2}{*}{ April } & EXM & 18.23 & -15.00 & -18.10 & 16.31 & -14.42 & -11.47 & 1.95 \\
\hline & & 41.34 & 43.92 & & 28.38 & 45.94 & 24.59 & 10.47 \\
\hline \multirow[t]{2}{*}{ May } & $2 \mathrm{~F}$ & 3.58 & -1.03 & -2.25 & 4.63 & -3.27 & 1.73 & 1.57 \\
\hline & & 15.35 & 15.90 & & 9.54 & 15.92 & 10.26 & 5.19 \\
\hline \multirow[t]{2}{*}{ May } & $2 \mathrm{M}$ & 7.78 & -7.31 & -1.94 & 8.68 & 2.97 & 7.85 & 6.53 \\
\hline & & 12.72 & 13.96 & & 12.27 & 13.89 & 9.78 & 5.87 \\
\hline \multirow[t]{2}{*}{ May } & $\mathrm{LF}$ & 6.51 & -6.24 & -2.13 & 8.95 & -3.03 & 3.95 & 3.69 \\
\hline & & 19.28 & 19.45 & & 16.24 & 20.19 & 13.37 & 5.36 \\
\hline \multirow[t]{2}{*}{ May } & EXM & 18.10 & -14.20 & -4.28 & 19.78 & -7.98 & -0.56 & 1.67 \\
\hline & & 35.40 & 37.02 & & 31.92 & 26.47 & 20.27 & 7.50 \\
\hline \multirow[t]{2}{*}{ June } & $2 \mathrm{~F}$ & 13.20 & 12.61 & 2.34 & 12.66 & 9.80 & 6.08 & 3.08 \\
\hline & & 22.61 & 23.51 & & 17.91 & 19.49 & 11.84 & 5.95 \\
\hline
\end{tabular}


Table 5: (Continued)

\begin{tabular}{|c|c|c|c|c|c|c|c|c|}
\hline \multirow[b]{2}{*}{$\begin{array}{l}\text { Option } \\
\text { month }\end{array}$} & \multirow[b]{2}{*}{$\begin{array}{l}\text { Trade initiation } \\
\text { day, } t\end{array}$} & \multicolumn{3}{|c|}{ Portfolio/strategy } & \multicolumn{3}{|c|}{ Portfolio/strategy } & \multirow[b]{2}{*}{$\begin{array}{l}\text { covered call } \\
I M P\end{array}$} \\
\hline & & $A S(C N)$ & $N I$ & SEP500 & $\begin{array}{l}A S P M \\
(C N)\end{array}$ & $\begin{array}{l}\text { on et al. }{ }^{2} \\
O M P\end{array}$ & $A M P$ & \\
\hline \multirow[t]{2}{*}{ June } & $2 \mathrm{M}$ & 11.11 & 14.11 & 1.60 & 14.42 & 8.97 & 5.13 & 1.73 \\
\hline & & 20.78 & 21.48 & & 16.74 & 13.81 & 7.62 & 3.49 \\
\hline \multirow[t]{2}{*}{ June } & $\mathrm{LF}$ & 13.29 & 20.34 & 14.73 & 18.76 & 14.67 & 7.86 & 2.90 \\
\hline & & 34.07 & 39.00 & & 21.90 & 19.96 & 12.64 & 9.33 \\
\hline \multirow[t]{2}{*}{ June } & EXM & 16.99 & 27.28 & 23.37 & 29.70 & 21.47 & 9.56 & 3.10 \\
\hline & & 37.26 & 43.92 & & 37.74 & 30.36 & 19.58 & 12.10 \\
\hline \multirow[t]{2}{*}{ July } & $2 \mathrm{~F}$ & 9.71 & 8.47 & 4.09 & 11.16 & 7.85 & 4.28 & 1.58 \\
\hline & & 23.36 & 24.29 & & 12.44 & 14.57 & 9.89 & 5.03 \\
\hline \multirow[t]{2}{*}{ July } & $2 \mathrm{M}$ & 12.55 & 8.44 & 5.71 & 13.48 & 8.97 & 5.98 & 2.34 \\
\hline & & 17.05 & 18.52 & & 11.46 & 16.63 & 10.97 & 6.02 \\
\hline \multirow[t]{2}{*}{ July } & LF & 8.71 & 3.02 & 4.26 & 10.69 & 6.46 & 3.87 & 1.95 \\
\hline & & 15.15 & 17.72 & & 11.03 & 21.36 & 13.89 & 7.13 \\
\hline \multirow[t]{2}{*}{ July } & EXM & 15.56 & 6.75 & 8.74 & 17.74 & 13.97 & 7.57 & 3.78 \\
\hline & & 19.23 & 20.38 & & 15.75 & 36.26 & 24.68 & 11.14 \\
\hline \multicolumn{9}{|c|}{ Aggregate: } \\
\hline \multicolumn{2}{|c|}{ average PROI } & 9.05 & 1.00 & 1.53 & 11.20 & 1.96 & 2.43 & 2.14 \\
\hline \multicolumn{2}{|c|}{ Average St. Dev. } & 22.64 & 25.07 & & 19.05 & 22.48 & 14.34 & 7.74 \\
\hline
\end{tabular}

distribution of options open interest. This advantage seems pervasive and does not seem to come at the cost of significantly higher risk.

\section{SUMMARY AND \\ CONCLUDING REMARKS}

This paper finds the prediction of stock price movement based on the distribution of options open interest to have reasonably good accuracy. In the sample, the open interest-based active trading strategies generate better returns compared with the passive benchmarks. The stock only active strategy yields significantly higher return than the S\&P500 and the naivve investor's buy and hold strategy involving the sample stocks. Since the hypothetical learner investor faces the risk of incorrect information or inaccurate learning, the investor might prefer limited risk speculative strategies involving stock plus options. In this context, the benchmark is a Merton et al.-style ${ }^{24}$ covered call strategy. Here also, it is found that the open 
interest-based active strategy provides a significantly higher return than do the passive covered call strategies.

Not only does the risk of the active strategies (naked and limited risk) seem close to the risk of the benchmarks, the magnitude of the return advantage seems too high to be nullified by any risk disadvantage there may be owing to the use of a rough proxy for risk in this paper. It is therefore concluded that the equity options open interest contains valuable information that is attractive for trading purposes.

The evidence has important implications for researchers and practitioners. The information content of derivative market activity found in this paper lends support to a growing theoretical and empirical literature. Many in this literature ${ }^{1-5,20,23}$ suggest that derivatives such as options cannot be considered redundant in the context of asymmetric and differential information or differential interpretation of information. In fact, as suggested by Cherian and Vila, ${ }^{25}$ Cherian $^{26}$ and Cherian and $\mathrm{Weng}^{27}$, informed traders in possession of volatility-related information can only use the options market, and this may have implications for the information content of the option prices and options market activity.

The evidence in this paper concerns directional trading only and has ignored volatility trading. Given that even these simpler trading strategies seem to indicate a high information content of derivatives market activity, it is expected that the information content will be even greater once more complex strategies based on the prediction of direction as well as volatility are entertained.

This paper shows one clear advantage of using derivatives market activity instead of prices to impart information. The

information implied from the derivative prices is about the risk-neutral distribution of the underlying asset. While it is certainly useful in many applications, in many other applications it is the physical distribution of the asset that is of most interest. Similarly, practitioners interested in estimating the beta and the cost of capital will find information about the physical distribution more useful.

Lastly, it should be mentioned that only US equity options and only one measure of activity in this market - namely the open interest - were considered. It remains to be seen how the approach will work in the context of options on other assets (such as foreign exchange, fixed income and commodity), derivatives of other types (such as futures and futures options) and derivatives traded in other countries.

\section{References}

1 Copeland, T. E. and Galai, D. (1983) 'Information Effects and the Bid-Ask Spread', Journal of Finance, Vol. 38, pp. 1457-1469.

2 Glosten, L. and Milgrom, P. (1985) 'Bid, Ask, Transaction Prices in a Specialist Market with Heterogeneously Informed Traders', Journal of Financial Economics, Vol. 13, pp. 71-100.

3 Easley, D. and O'Hara, M. (1987) 'Prices, Trade Size, and Information in Security Markets', Journal of Financial Economics, Vol. 19, pp. 69-90.

4 Kyle, A. (1985) 'Continuous Auctions and Insider Trading', Econometrica, Vol. 53, pp. 1315-1335.

$5 \mathrm{He}, \mathrm{H}$. and Wang, J. (1995) 'Differential Information and Dynamic Behavior of Stock Trading Volume', Review of Financial Studies, Vol. 8, pp. 919-972.

6 Copeland, T. E. (1976) 'A Model of Asset Trading Under the Assumption of Sequential 
Information Arrival', Journal of Finance, Vol. 31, pp. 1149-1168.

7 Black, F. (1975) 'Fact and Fantasy in Use of Options', Financial Analysts Journal, Vol. 31, pp. 36-41, 61-72.

8 Grossman, S. (1988) 'An Analysis of the Implications for Stock and Futures Price Volatility of Program Trading and Dynamic Hedging Strategies', Journal of Business, Vol. 61, pp. 275-298.

9 Detemple, J. and Selden, L. (1991) 'A General Equilibrium Analysis of Option and Stock Market Interactions', International Economic Review, Vol. 32, pp. 279-302.

10 Back, K., Cao, H. and Willard, G. (2000) 'Imperfect Competition Among Informed Traders', Journal of Finance, Vol. 55, pp. 2117-2155.

11 Biais, B. and Hillion, P. (1994) 'Insider and Liquidity Trading in Stock and Options Markets', Review of Financial Studies, Vol. 7, pp. 743-780.

12 Brennan, M. J. and Cao, H. (1996) 'Information, Trade, and Derivative Securities', Review of Financial Studies, Vol. 9, pp. 163-208.

13 Manaster, S. and Rendleman, R. J. (1982) 'Option Prices as Predictors of Equilibrium Stock Prices', Journal of Finance, Vol. 37, pp. 1043-1057.

14 Bhattacharya, M. (1987) 'Price Changes of Related Securities: The Case of Call Options and Stocks', Journal of Financial and Quantitative Analysis, Vol. 22, pp. 1-15.

15 Vijh, A. M. (1990) 'Liquidity of the CBOE Equity Options', Journal of Finance, Vol. 45, pp. 1157-1179.

16 Anthony, J. (1988) 'The Interrelation of Stock and Options Market Trading - Volume Data', Journal of Finance, Vol. 43, pp. 949-964.

17 Stephan, J. A. and Whaley, R. E. (1990) 'Intraday Price Change and Trading Volume Relations in the Stock and Stock Options Markets', Journal of Finance, Vol. 44, pp. 115-134.
18 Sheikh, A. M. and Ronn, E. I. (1994) 'A Characterization of the Daily and Intraday Behavior of Returns on Options', Journal of Finance, Vol. 49, pp. 557-580.

19 John, K., Koticha, A. and Subrahmanyam, M. (1993) 'The Micro-structure of Options Markets: Informed Trading, Liquidity, Volatility, and Efficiency', Working Paper, New York University, NY.

20 John, K., Koticha, A., Narayanan, R. and Subrahmanyam, M. (2000) 'Margin Rules, Informed Trading in Derivatives and Price Dynamics', Working Paper, New York University, NY.

21 Mayhew, S., Sarin, A. and Shastri, K. (1995) 'The Allocation of Informed Trading Across Related Markets: An Analysis of the Impact of Changes in Equity-option Margin Requirements', Journal of Finance, Vol. 50, pp. 1635-1653.

22 Leisen, D. and Judd, K. (2001) 'Equilibrium Open Interest', Working Paper, Faculty of Management, McGill University, Canada.

23 Easley, D., O'Hara, M. and Srinivas P. S. (1998) 'Option Volume and Stock Prices: Evidence on where Informed Traders Trade', Journal of Finance, Vol. 53, pp. 431-465.

24 Merton, R. C., Scholes, M. and Gladstein, M. (1978) 'The Returns and Risk of Alternative Call Option Portfolio Investment Strategies', Journal of Business, Vol. 51, pp. 183-242.

25 Cherian, J. A. and Fremault Vila, A. (1997) 'Information Trading, Volatility, and Liquidity in Options Markets', AIMR Publication Series, Charlottesville, VA, The Research Foundation of the Institute of Chartered Financial Analysts.

26 Cherian, J. A. (1998) 'Discretionary Volatility Trading in Option Markets', Working Paper, Boston University, MA.

27 Cherian, J. A. and Weng, W. Y. (1998) 'An Empirical Analysis of Directional and Volatility Trading in Options Markets', Working Paper, Boston University, MA. 